\title{
Conciencia y paralelismo en Spinoza
}

\author{
Luis Ángel García Muñoz \\ Departamento de Filosofía \\ Universidad Autónoma de Aguascalientes \\ garcialuisangel87@gmail.com
}

En su obra más representativa, la Ethica ordine geometrico demostrata (específicamente en su segunda parte), Spinoza sugiere que todo individuo, sea humano, animal o un objeto extenso cualquiera, está animado en cierto grado ( $E$ IIP13s). Y por si fuera poco, que los individuos inferiores como animales $u$ objetos extensos tienen mente.

Este asunto, potencialmente agresivo para el sentido común, es tratado por Edwin Curley, quien trata de ofrecer una distinción entre los hombres y los demás individuos con la finalidad de explicar el sistema de Spinoza sin caer en sugerencias tan problemáticas. Esta distinción se encuentra en su libro Spinoza's Metaphysics: An Essay in Interpretation publicado en 1969, en el que defiende que, en Spinoza, todos los individuos que están en Dios tienen mente. Pero los hombres se distinguen de los demás individuos (rocas, animales, etc.) porque sólo los primeros, además de tener mente, tienen conciencia. Lo que caracteriza a la conciencia en Spinoza, según Curley, es la posesión de ideas de ideas o bien de proposiciones de proposiciones. ${ }^{1}$ Así, aunque todos los individuos, en Spinoza tengan mente, los hombres se distinguen de los demás individuos porque sólo ellos poseen ideas de ideas o proposiciones de proposiciones.

\footnotetext{
${ }^{1}$ Esta caracterización de la conciencia es adoptada por Curley al haber reinterpretado la teoría de las ideas en Spinoza y al haber encontrado en ellas 'un elemento de afirmación' que permite equipararlas con las proposiciones. Lamentablemente Curley no explica con profundidad lo que entiende por proposición o aserción. Lo único que podemos decir es que concibe a las proposiciones o a la aserciones como dotadas de un carácter de afirmación y negación que posibilita el vínculo con las ideas de Spinoza (ver 1969; 121).
} 
La pretendida solución de Curley a la problemática, y tal vez excéntrica tendencia a afirmar que todos los individuos tienen mente, suscita una serie de respuestas que conforman una de las polémicas principales en torno a Spinoza actualmente. Entre los principales participantes en esta polémica se encuentran Margaret Dauler Wilson, Jonathan Bennett y Don Garrett, quienes atienden al problema que Curley plantea y tratan de darle solución por medio de una reinterpretación del papel de la conciencia en tan riguroso sistema.

Al analizar las críticas a Curley, argumentaré tres puntos: primero, que a la solución presentada por Curley, y a la presentada posteriormente por Bennett, subyace una noción de paralelismo en la que aquello que expresa la modificación de determinado atributo es, en última instancia, una cosa singular (roca, círculo, etc.); segundo, al analizar las críticas a Curley por parte de Wilson, veremos que tanto la respuesta de Curley como la de Bennett, al estar basadas en dicha noción de paralelismo, omiten el papel de Dios en el sistema como aquello expresado en última instancia por cualquier modificación de algún atributo divino; respecto a esto defenderemos que hay dos visiones al paralelismo, una en la que las modificaciones expresan una cosa singular de dos maneras distintas y otra en la que las modificaciones expresan a Dios de diversas maneras, de lo que se desprende que la primera es una visión inadecuada; y tercero, que el error fundamental de Curley y Bennett parte de la falta de distinción entre la doctrina del paralelismo y la doctrina de la identidad de modo, que bien describe Garrett. Así, apostaremos a que la distinción entre el hombre y los demás individuos en Spinoza no radica en que se tenga o no mente consciente, sino en el grado de conciencia de cada individuo; esto último gracias al naturalismo incremental propuesto por Garrett. 


\section{Bennett y Curley: ideas de ideas, autoconocimiento y paralelismo ${ }^{2}$}

Jonathan Bennett, autor de A Study of Spinoza's Ethics, acepta la importancia de asumir la doctrina del paralelismo que está manifestada en la Ethica para poder examinar el tema de la mente en Spinoza. En los objetivos de A Study of Spinoza's Ethics, Bennett dice: «al asumir la doctrina del paralelismo [de Spinoza] [...] examinaré sus puntos de vista acerca de los aspectos cognitivos de la mente» (1980; $\left.153^{3}\right)$. La importancia del paralelismo en estos temas radica en que sólo a través de éste se entiende a la mente humana. Cuando Spinoza define a la mente humana como algo que está constituido de la idea de una cosa singular existente en acto (E IIP11), para luego decir que esa cosa singular existente en acto que conforma a la mente humana es su cuerpo ( $E$ IIP13), presupone que a cada cuerpo o modo del atributo de la extensión le sigue, en orden y conexión (paralelismo (E IIP7)), una idea o un modo del atributo del pensamiento.

El paralelismo se caracteriza comúnmente, según Bennett, por ser una doctrina en la que «cada idea es paralela a un ítem físico que es su objeto» (1980; 153). Bajo esta visión de paralelismo Spinoza hablaría de ideas de tal o cual objeto físico. Bennett lo ejemplifica al decir que si ( $\mathrm{x}$ ) es el objeto físico e ' $\mathrm{I}$ ' la idea, entonces $\mathrm{I}(\mathrm{x})$ es la idea del objeto físico. Donde $\mathrm{I}(\mathrm{x})$ representa a $(\mathrm{x})$, mas $(\mathrm{x})$ no representa a $\mathrm{I}(\mathrm{x})$. Pese a esta exposición común, Bennett encuentra un asunto conflictivo con el paralelismo en el propio Spinoza: las ideas de ideas. Según Bennett, el sistema de Spinoza muestra que la idea no tiene que ser exclusivamente de algún objeto físico o modo de la exten-

\footnotetext{
${ }^{2}$ Christopher Martin afirma que la teoría de las ideas de ideas de Curley (o proposiciones de proposiciones - aceptando la equivalencia propuesta por el autor) en relación a Spinoza recibe 'objeciones serias' por parte de Margaret D. Wilson y Jonathan Bennett. La objeción que sugiere Martin por parte de Bennett no es tal y por lo tanto la afirmación de Martin requiere atenuarse. Si bien Bennett propone una interpretación alternativa al tema de las ideas de ideas en Spinoza, no objeta directamente a Curley (ya que no lo menciona). Pese a esto, Bennett aborda asuntos interesantes que vale la pena señalar en contraste con la interpretación de la doctrina de las ideas de ideas de Curley para mostrar que a ambos les subyace una noción de paralelismo en la que una modificación de un atributo divino no expresa a Dios, sino a una cosa singular (ver Martin 2007; 269).

${ }^{3}$ Todas las traducciones de los textos en inglés fueron realizadas por el autor.
} 
sión, sino de cualquier cosa que exista y que, por lo tanto, esté en Dios. Bennett justifica lo anterior con ayuda de la proposición III de la segunda parte de la Ethica donde se postula que en «Dios se da necesariamente la idea tanto de su esencia, cuanto de todo lo que se sigue necesariamente de su esencia». La demostración de la presente explica que Dios puede una infinidad de cosas en infinitos modos y que de cada una de ellas forma una idea de infinitos modos ( $E$ IIP3D). Como todo está en Dios y todo se sigue necesariamente de su esencia (incluyendo modificaciones de otros atributos además del de la extensión) (E IP15), de todo lo que exista, hay una idea en Dios. Por lo que las ideas de no son sólo de modificaciones de la extensión, sino de cualquier cosa existente sin importar a qué atributo pertenezca. Debido a que el hombre sólo puede conocer dos atributos a través de sus respectivas modificaciones (atributo de la extensión y del pensamiento) podemos afirmar que además de haber ideas de los modos del atributo de la extensión, hay ideas de modos del atributo del pensamiento, esto es: ideas de ideas.

Debido a que puede haber ideas de ideas y no solamente ideas de objetos físicos, la noción de paralelismo que se caracteriza por la relación de identidad entre un modo extenso y un modo del pensamiento defendida, por ejemplo, por personajes como Curley, está en riesgo, ya que las ideas de ideas serían una anomalía en el sistema de Spinoza que se basa en la noción del paralelismo extensión-pensamiento. El paralelismo para Curley es la «noción de Spinoza de que el modo de la extensión y la idea de ese modo son una y la misma cosa, expresada por dos maneras diferentes» $(1969 ; 120)$. Para Curley hay una idea que corresponde a cada modo del atributo de la extensión, esto es I(x). Para Bennett la idea no tiene que ser exclusivamente del objeto físico o modo de la extensión, sino de cualquier cosa que exista y que, por lo tanto, esté en Dios.

En el anterior sentido Bennett sugiere que la doctrina del paralelismo en Spinoza no trata meramente de la relación entre pensamiento-extensión (como la contempla Curley, por ejemplo), sino de una relación que posibilita el paralelismo entre todo (cualquier modificación de cualquier atributo divino, incluido el pensamiento) y el pensamiento (thought-everything parallelism (1980; 153)). Pero antes de afirmar tal cosa, Bennett nota que necesita aceptar que $\mathrm{I}(\mathrm{I}(\mathrm{x}))$ 
(o la idea de la idea del objeto físico (x)) se relaciona con $\mathrm{I}(\mathrm{x})$ de la misma manera en que $\mathrm{I}(\mathrm{x})$ se relaciona con $(\mathrm{x})(1980 ; 184)$. Esto es, necesita mostrar que si hay ideas de ideas en el sentido en que él dice, debe considerar que éstas concuerden con la doctrina del paralelismo expresada en la proposición VII de la segunda parte de la Ethica donde una idea de una idea deberá tener «el mismo orden y conexión» que una idea que no sea de una idea. La proposición dice así: «El orden y conexión de las ideas es el mismo que el orden y conexión de las cosas [rerum]» ( $E$ IIp7). En caso de que no se muestre esta relación coherente de las ideas de ideas con el paralelismo (por lo menos con la noción que Curley acepta), éstas podrían ser un elemento peligroso para la coherencia del sistema de Spinoza, puesto que si bien el paralelismo (por lo menos para Curley) indica una relación de identidad entre un modo del atributo del pensamiento y uno de la extensión, las ideas de ideas no cabrían en el mismo ya que no son ideas de objetos físicos. Pero, en la proposición VII ¿a qué se refiere Spinoza con cosas (rerum)? Podríamos decir que comúnmente por 'cosa' se entiende una modificación extensa, pero bajo la luz de la dilucidación de Bennett podríamos decir que cosa (rerum $)^{1}$ no sólo se refiere a una modificación del atributo de la extensión, sino de cualquier atributo. Así, la coherencia de las ideas de ideas con el paralelismo está asegurada pero sólo en cierto grado. $\mathrm{Si}$ concebimos a las cosas no como modificaciones de la extensión, sino de cualquier atributo, se abre la posibilidad de que las ideas de ideas exhiban el mismo orden y conexión con ideas que no son de ideas (1980; 185). Para reforzar esta posibilidad Bennett recurre a lo que denomina «el paralelismo de las cadenas causales» (1980; 185).

El paralelismo de las cadenas causales, indica que en Dios, la única substancia, hay un solo orden (si hubiera varias substancias, cosa imposible en la Ethica, habría varios órdenes), y que toda cadena causal que se encuentre en él, sigue ese mismo orden. Así, «I $(\mathrm{I}(\mathrm{x}))$ se sigue en Dios de la misma manera y dice relación a Dios de la misma manera que $\mathrm{I}(\mathrm{x})$ » $(1980 ; 185)$. $\mathrm{I}(\mathrm{I}(\mathrm{x}))$ y I(x) están en la

\footnotetext{
${ }^{1}$ La palabra rerum es una declinación de res. Ésta indica una 'cosa' que no necesariamente tiene que ser extensa. Como ejemplo vale mencionar la res cogitans y la res extensa de Descartes.
} 
misma cadena causal debido a 1) que están en la misma substancia y 2) debido a que tanto $\mathrm{I}(\mathrm{I}(\mathrm{x})$ ) como $\mathrm{I}(\mathrm{x})$ pertenecen al mismo atributo ya que ambos son ideas de algo (ya sea de una modificación de la extensión o del pensamiento). 2) se justifica con el siguiente fragmento: «La mente y el cuerpo son uno y el mismo individuo que se concibe ya bajo el atributo del pensamiento, ya bajo el de la extensión; por eso, la idea de la mente y la mente misma son una y la misma cosa que se concibe bajo uno y el mismo atributo: el del pensamiento» (E IIP21s).

Si aceptamos la substitución entre idea y mente que Curley propone diremos que la idea de la mente es una idea de una idea y que tanto la primera como la segunda pertenecen al mismo atributo, por lo que pertenecen a la misma cadena causal. Bennett ejemplifica una cadena causal como una columna compuesta por varios niveles. Cada uno de esos niveles es idéntico a los demás. Si $(\mathrm{I}(\mathrm{x})$ ) y $\mathrm{I}(\mathrm{x})$ son dos niveles de una misma columna, entonces ambos niveles se siguen de y se relacionan con Dios de la misma manera, por lo que cada nivel es idéntico al otro nivel en cierto sentido. Pese a esto Bennett considera que cada nivel se distingue del otro debido a que cada nivel representa algo distinto. Pero esto no quiere decir que por representar cosas distintas sean de distintas cadenas causales, ya que cada nivel que representa algo distinto de otro a la vez comparte propiedades intrínsecas idénticas con los demás niveles de una misma cadena causal.

Si cada nivel en la columna representa solamente a su vecino inmediato de abajo. Entonces los niveles son distintos de uno y otro porque lo que representan es distinto [...]. Esto podría ser consistente con el paralelismo de similitudes y cadenas causales, sólo en cuanto podemos permitir que $\mathrm{I}(\mathrm{I}(\mathrm{x}))$ y $\mathrm{I}(\mathrm{x})$ sean exactamente iguales intrínsecamente aunque desiguales en lo que representan $(1980 ; 186)$.

Bennett ejemplifica esto de la siguiente manera: nos tomamos una fotografía. Luego le tomamos una foto a tal fotografía. Después tomamos otra de la fotografía de la fotografía. Cada una representa individualmente a lo inmediato anterior de esa línea causal. Esto es, a la foto de la fotografía, o a la fotografía, o a la persona fotogra- 
fiada. Las fotos de las fotografías, aunque representan algo inmediatamente, representan algo intrínsecamente, esto es, a nosotros o a la persona fotografiada. Si las fotografías fueran ideas, diríamos que del objeto físico $(\mathrm{x})$ se sigue una idea $\mathrm{I}(\mathrm{x})$, a su vez una idea de la idea $\mathrm{I}(\mathrm{I}(\mathrm{x}))$, luego una idea de la idea de la idea $\mathrm{I}(\mathrm{I}(\mathrm{I}(\mathrm{x})))$ y así consecutivamente. Cada nivel de una cadena causal como la de las fotografías o la de las ideas representan a su vecino inmediato. Esto es, $\mathrm{I}(\mathrm{I}(\mathrm{I}(\mathrm{x}))$ ) representa inmediatamente a $\mathrm{I}(\mathrm{I}(\mathrm{x}))$ y no al objeto físico $(x)$. Pero cada nivel, aunque representa cosas distintas, contiene cualidades intrínsecas que los identifica como dentro de una sola cadena causal, esto es (x), o la persona fotografiada.

Si bien los niveles de las cadenas causales contienen de manera intrínseca algo que los identifica, este algo es, en última instancia, un objeto extenso. Por lo que I(I(x)) (una idea de una idea) tiene el mismo orden y conexión que $\mathrm{I}(\mathrm{x})$ ya que ambos niveles parten del mismo objeto extenso.

A partir de lo anterior podemos ver que la visión del paralelismo de Bennett corresponde a que los modos de cualquier atributo expresan en última instancia a una cosa singular (reloj, roca, etcétera). Así, aunque la visión del paralelismo de Curley no concuerde con la de Bennett debido a que la primera no considera el orden y conexión de las ideas de ideas y la segunda sí, podemos decir que ambas concuerdan en que aquello que expresa cada modificación de cualquier atributo es una cosa singular, y no a Dios mismo que es inherente a todas las modificaciones de cualquier atributo. Entonces, el paralelismo tanto para Bennett como para Curley corresponde en cierto sentido a una sola clase de paralelismo donde se omite la inherencia de Dios. El caso de Bennett se ejemplifica al considerar que cada nivel de una cadena causal se asimila a otro nivel de la misma cadena por tener la misma propiedad intrínseca. Esto es, la representación de un objeto extenso en particular. Si bien Bennett considera que las cadenas causales tienen el mismo orden y conexión que otras cadenas causales ya que todas ellas están en Dios, quien procede con un solo orden al que se somete todo lo que está en él, cada cadena $(\mathrm{I}(\mathrm{I}(\mathrm{I}(\mathrm{x}))), \mathrm{I}(\mathrm{I}(\mathrm{x}))$, $\mathrm{I}(\mathrm{x}),(\mathrm{x}))$ goza de una cualidad intrínseca que no es propiamente el «estar en Dios», sino el objeto extenso que las identifica. 
Bennett apuesta por su teoría de la representación de los niveles de ciertas cadenas causales debido a que Spinoza dice: «la idea de la idea no es otra cosa que la forma de la idea en cuanto se considera a ésta como un modo de pensar sin relación al objeto» (E IIP21s). Bennett interpreta que Spinoza habla de que la forma de una idea y la idea son modificaciones del atributo del pensamiento. Pero la idea de la idea (o la forma de la misma) toma como particularidad intrínseca a la idea y no al contenido de la idea (a lo que representa). Esto es, Spinoza según Bennett, al postular que la idea de una idea no es más que la forma de la segunda, afirma que $\mathrm{I}(\mathrm{I}(\mathrm{x}))$ es la forma de $\mathrm{I}(\mathrm{x})$ pero nada más. La idea de la idea no se relaciona con el objeto extenso (o con (x)), por lo que la idea de la idea toma como propiedad intrínseca no al objeto extenso (x) sino a I(x). En cambio Bennett cree que la doctrina de Spinoza acerca de las ideas de las ideas como forma de una idea necesita la apropiación de la representación para que se pueda relacionar con el paralelismo extraído de la proposición VII de la segunda parte (donde se dice que las ideas deben de tener el mismo orden y conexión que las cosas - entendidas como una modificación de cualquier atributo, no sólo de la extensión) y así resguarde la coherencia del sistema de Spinoza y no represente un peligro.

En el caso de que no se considerara la aportación de la representación y las propiedades intrínsecas que sugiere Bennett, la teoría de las ideas de ideas en Spinoza podría ser peligrosa en el sentido en que se mostraría que el paralelismo es insuficiente para el sistema debido a que las modificaciones de determinado atributo (entendidas a manera de cadenas causales) no tienen el mismo orden y conexión que las demás modificaciones de determinado atributo (las demás cadenas causales). Las cadenas causales no tendrían la misma conexión debido a que las ideas de ideas no se relacionan (ni directa, ni indirectamente) con el objeto extenso. Claro está que al considerar la teoría de Bennett acerca de la representación y las propiedades intrínsecas, se soluciona la falta de conexión ya que en efecto la idea de una idea es la forma de una idea sin relación al objeto extenso, pero sólo a modo de representación; tanto la idea de una idea como la idea, tienen cualidades intrínsecas que resguardan la conexión con los demás atributos ((x) o el objeto extenso). Visiones como las anterio- 
res en las que se subraya la importancia de que las ideas de ideas se relacionen con el objeto extenso, marcan la clase de interpretación de la doctrina del paralelismo en la que se mueve Bennett, esto es, en la que las modificaciones expresan cosas singulares y no a Dios.

La doctrina de las ideas de las ideas, para Bennett, no es sólo peligrosa en el sentido en que puede mostrar que no hay un orden y conexión entre ideas y cosas (no en el sentido que se limita a la extensión), sino también en el sentido de que se puede hablar de una realidad equiparada entre el campo de lo mental y el campo de lo físico. Bennett, al mostrar evidencia para interpretar la doctrina del paralelismo de tal manera que suscite una relación entre todo (cualquier modificación de cualquier atributo) y el pensamiento (thought -everything parallelism), abre las puertas a una problemática tal vez secundaria para Bennett, tal consiste en considerar que «hay tanta realidad en el campo de lo físico, como en el de lo mental» (1980; 185). Si bien todo aquello que existe tiene una idea, podemos adjudicarle la misma existencia o realidad a I(x) que a (x), lo que implica que podemos decir que todo en el campo de lo físico tiene la misma realidad que todo en el campo de lo mental. ${ }^{2}$

Parece que la 'problemática' de la que se percata Bennett es suscitada por no tener clara una noción de realidad y existencia (si aceptamos tal vez una equivalencia de términos). En efecto podemos ver que resultaría confuso concebir a $(x)$ e I $(x)$ con la misma realidad si concebimos a la realidad como aquello que concuerda con las condiciones materiales de la experiencia o sensación. Pero si atendemos a la realidad como Spinoza la entiende esta complicación se disuelve.

Spinoza dice: «Cuanto más de realidad o ser tiene cada cosa, tantos más atributos le competen» (E Ip9). Así, el criterio de que algo sea más real que otra cosa es la cantidad de atributos que le competen a cada cosa. Puesto que a Dios le competen infinitos atributos, tendrá más realidad que ninguna otra cosa. Si seguimos la

\footnotetext{
${ }^{2}$ A la luz de la interpretación de ideas de ideas en Spinoza de Bennett, podríamos decir que si $\mathrm{I}(\mathrm{x})$ existe, $\mathrm{I}(\mathrm{I}(\mathrm{x}))$ también. Lo anterior al considerar a $\mathrm{I}(\mathrm{x})$ e $\mathrm{I}(\mathrm{I}(\mathrm{x}))$ como modificaciones del atributo del pensamiento. En cambio, para Curley si $(\mathrm{x})$ existe, entonces $\mathrm{I}(\mathrm{x})$ también, donde (x) es un modo del atributo de la extensión e I(x) es uno del pensamiento (ver 1980; 185).
} 
problemática de Bennett, entre I(x) que se encuentra en el campo de lo mental y (x) que se encuentra en el campo de lo material, ¿cuál tiene más realidad? Diríamos que como a ambos les pertenece un solo atributo (extensión o pensamiento respectivamente), entonces tienen la misma realidad, o bien, no hay uno más real que otro. En cambio, si contraponemos un cuerpo extenso complejo, digamos un reloj con maquinaria sofisticada, con uno menos complejo, como un tornillo, diríamos que el reloj tendría más realidad que el tornillo debido a que el reloj participa en mayor medida del atributo de la extensión que el tornillo. Ese grado de complejidad otorga mayor o menor realidad en comparación o contraste entre dos modos del mismo atributo. Así, si Dios es lo más complejo, no hay nada tan real como él.

Bennett titubea en una solución a tal problema y dice que entre dos modificaciones de distintos atributos, ninguno tiene más realidad que el otro, sino la misma:

Sugeriría que $\mathrm{I}(\mathrm{x})$ tiene tanta realidad como $\mathrm{x}$, dándole así [suponiendo que existen dos columnas, una para lo físico y la otra para lo mental y que en la primera está el objeto físico y en la segunda la idea de ese objeto, la idea de la idea de ese objeto, etc.] a cada columna de lo mental exactamente tanta realidad como al correspondiente disco físico (1980; 185).

Pese a esta solución que posiblemente compaginaría con la noción de realidad manifestada en la Ethica, Bennett no está conforme y aún le resulta confuso. Tal confusión puede ser motivada por una concepción de la realidad distinta a la que Spinoza expone en su obra más representativa. Es por ello que Bennett no ahonda seriamente en esta problemática y la deja como una provocación en un plano inferior a la problemática del orden y conexión entre ideas y cosas a la que sí da una solución al considerar el elemento de la representación bajo la luz de las propiedades intrínsecas como fructífero en el sistema de Spinoza.

Hasta aquí podemos observar que la doctrina de las ideas de ideas cobra sentidos diferentes tanto en Bennett como en Curley. Para el segundo las ideas de ideas sirven como condición para distinguir 
entre individuos conscientes y no conscientes. Para el primero las ideas de ideas suscitan concebir al paralelismo no sólo como una relación entre pensamiento y extensión, sino entre pensamiento y todo (cualquier modificación de cualquier atributo). Al seguir el sentido que Bennett otorga a la doctrina de las ideas de ideas, encontraremos que aunque en un primer momento ninguno de los dos sentidos parecen iguales, ambos convergen momentáneamente en un punto similar que después necesitará una distinción tajante, esto es, el asunto de la conciencia y el conocimiento.

Si supusiéramos que la teoría de Bennett acerca de la representación y las propiedades intrínsecas es falsa, entonces presenciaríamos nuevamente la problemática correspondiente a que las ideas de ideas pueden resultar peligrosas para el sistema de Spinoza a través del paralelismo (relación entre ideas y cosas). Pese a esto, si la doctrina de las ideas de ideas está en el sistema es porque juega un papel dentro del mismo. ¿Cuál es este papel? Bennett dice que «la doctrina de las ideas de ideas es para servir como una teoría del autoconocimiento» (1980; 188). ${ }^{3}$ Bennett lo describe de la siguiente manera: «que yo tenga ideas de mis propias ideas es [la] manera de decir [de Spinoza] que yo tengo conocimiento no sólo del mundo físico, sino también de mi propia mente» $(1980 ; 188)$.

Si recordamos la definición de mente humana que nos da Spinoza, bien podríamos concordar con Bennett en cuanto al uso de ideas de ideas. La proposición en la que radica este tema dice lo siguiente: «Lo primero que constituye el ser actual de la mente humana no es nada más que la idea de una cosa singular existente en acto» ( $E$ IIP11). Al basarnos en que la mente humana contiene una idea de lo que pasa en nuestro cuerpo, y al considerar que tanto la mente como una idea son modos del atributo del pensamiento, se puede decir que en el momento en que la mente contiene la idea que la constituye, se tiene una idea de una idea de una cosa singular existente en acto, o bien, un modo del atributo del pensamiento de un modo del atributo del pensamiento de determinada cosa singular existente en acto. Cuando tenemos una idea de lo que pasa en

\footnotetext{
${ }^{3}$ Esto no implica que sólo nos conozcamos a nosotros mismos. También podemos conocer cosas externas a través de las afecciones que sufre nuestro cuerpo.
} 
nosotros, nos autoconocemos. Spinoza dice con respecto a las ideas de ideas: «en efecto, tan pronto como alguien sabe algo, sabe, por eso mismo, que lo sabe y, a la vez, sabe que sabe lo que sabe, y hasta el infinito» (E IIP21s). Es por ello que Bennett acepta que la doctrina de las ideas de ideas tiene una función en el sistema de Spinoza a manera de teoría del autoconocimiento. ${ }^{4}$

Edwin Curley con respecto a la doctrina de las ideas de ideas dice que el «conocimiento o la conciencia surgen sólo cuando la mente no contiene meramente ideas de las afecciones del cuerpo [puesto que sólo sería $\mathrm{I}(\mathrm{x})]$, sino también ideas de esas ideas [I(I(x))]» (1969; 126). Según lo anterior, en un primer momento, podríamos decir que Bennett y Curley compaginan con respecto a la función de la doctrina de las ideas de ideas en el sistema de Spinoza como conocimiento de sí y como conciencia de sí.

Bennett, al considerar a la doctrina de las ideas de ideas como funcional para una teoría del autoconocimiento, se remite a la proposición XII de la segunda parte de la Ethica: «Cuanto acontece en el objeto de la idea constituyente de la mente humana, debe ser percibido por la mente humana, o sea, de tal cosa se dará en la mente necesariamente la idea: esto es, si el objeto de la idea que constituye la mente humana, es un cuerpo, nada podrá acontecer en este cuerpo que no perciba la mente».

Con esta proposición, Bennett acepta que el sistema de Spinoza puede sugerir que todo aquello que pasa en nuestro cuerpo es percibido por nuestra mente. Si esta proposición, a la que le subyace la doctrina de ideas de ideas (puesto que la mente se percata de algo que pasa en nuestro cuerpo suscita tener un modo del atributo del pensamiento de un modo del atributo del pensamiento de una cosa existente en acto), se considera como representativa de una teoría de la conciencia, entonces, según Bennett, sería «absurdamente excesiva» (1980; 188), puesto que un hombre estaría consciente de cada hecho que acontezca en su cuerpo.

\footnotetext{
${ }^{4}$ La noción de la doctrina de las ideas de ideas para Bennett no se reduce al simple autoconocimiento, sino también al conocimiento de los objetos externos o del mundo físico: «that I have ideas of my own ideas is his [Spinoza's] way of saying that I have knowledge not only of the physical world but also of my own mind» $(1980 ; 188)$.
} 
Christopher Martin afirma, en un tono similar al de Bennett, que es «absurdo creer que mi mente es consciente, incluso en un nivel subconsciente, de cada estado físico que compone mi cuerpo, y si la teoría de Spinoza conlleva a esto, entonces debe ser incorrecta como una noción de conciencia» $(2007 ; 272)$.

El que Bennett y Martin estén de acuerdo en que si la doctrina de las ideas de ideas es una teoría de la conciencia conduciría a situaciones absurdas (ya que estaríamos conscientes del choque entre glóbulos blancos y rojos en el sistema circulatorio, por ejemplo), no implica que ésta sea una crítica directa a la tendencia de Curley por establecer a la doctrina de las ideas de ideas como criterio de distinción entre mentes conscientes y no conscientes. Incluso Curley acepta lo extravagante que resulta esta implicación (que estemos conscientes de todo lo que pasa en nuestros cuerpos).

Uno puede inferir $[\ldots]$ la sorprendente doctrina de que la mente es consciente [aware o conscious] de todo lo que pasa en el cuerpo. Eso parece ser lo que E IIP12 está diciendo. Si es así, los trabajos de los doctores serían un buen negocio y más fácil de lo que son. Su doctor no tendría que hacerle un examen de sangre para ver si su conteo de glóbulos blancos está bajo; simplemente le preguntaría. Esto es absurdo, y requeriríamos buena evidencia antes de atribuirle tal doctrina a Spinoza $(1969 ; 127)$.

Si bien Bennett es un crítico de la teoría de la conciencia que postula Curley basada en la doctrina de las ideas de ideas en Spinoza, ambos están de acuerdo en que una teoría de la conciencia fundamentada en la doctrina de las ideas de ideas en Spinoza es absurda en cuanto sugiera que estamos conscientes de todo lo que pasa en nuestro cuerpo. Entonces ¿cuál es la crítica de Bennett a Curley?

Bennett no niega que la doctrina de las ideas de las ideas cumpla una función en el sistema de Spinoza como autoconocimiento. Lo que niega es que se pueda hablar de conciencia en Spinoza en un sentido donde una mente humana sea consciente de todo aquello que pase en su cuerpo. De esta manera, Bennett se niega a sugerir que la doctrina de las ideas de ideas tenga una función en el sistema como conciencia y afirmará que tiene una función como autoconoci- 
miento. La distinción entre estos dos planos es obviada por Curley: el «conocimiento o la conciencia surgen sólo cuando la mente no contiene meramente ideas de las afecciones del cuerpo, sino también ideas de esas ideas» (1969; 127).

La diferencia principal entre Bennett y Curley es la distinción entre conocimiento y conciencia. Mientras el primero la hace, el segundo no. Bennett desarrolla esta distinción conceptual a través de dos preguntas: 1) ¿ese ítem mental ocurre conscientemente en su mente?; 2) ¿él sabe que el ítem mental está presente en su mente? (1980; 188). La pregunta 1) pertenece a la conciencia y la 2) al conocimiento.

Bennett aclara que aunque la proposición XII de la segunda parte de la Ethica sugiera que podemos percibir todo lo que pasa en el cuerpo pues la mente formará una idea de aquel y los demás acontecimientos, ello no quiere decir que en realidad sepamos todo lo que pasa en nuestro cuerpo. Lo anterior lo justifica al remitirse a ciertas proposiciones de la Ethica que postulan que el hombre no puede tener un conocimiento adecuado de su cuerpo. «La mente humana no envuelve un conocimiento adecuado de las partes componentes del cuerpo humano» (E IIP24). «La idea de la idea de una afección cualquiera del cuerpo humano no envuelve el conocimiento adecuado de la mente humana» (E IIP29). «[La mente humana] no tiene ni de sí misma, ni de su cuerpo, ni de los cuerpos externos un conocimiento adecuado, sino sólo mutilado y confuso» (E IIP29c).

Con tal evidencia, Bennett apuesta a que hablar de conciencia resulta más problemático que hablar de conocimiento en Spinoza. Si bien al referirnos a la pregunta 1) (¿ese ítem mental ocurre conscientemente en su mente?), podemos interpretar cierta omnisciencia (en el sentido en que se es consciente de cada ítem mental), la pregunta 2) (¿él sabe que el ítem mental está presente en su mente?) muestra que la omnisapiente no es la mente humana, sino sólo la divina. Así, la mente humana conoce o sabe que algunos ítems están presentes, pero a su vez ignora otros.

Debido a que cuando se habla de conciencia en Spinoza es posible entender que la mente tendría una idea de todo lo que acontece en su objeto, Bennett opta por hablar de conocimiento en lugar de conciencia. La doctrina de las ideas de ideas de Spinoza, para Bennett, 
es una doctrina que propicia una teoría de conocimiento de sí y no de conciencia de sí.

De este modo, podemos contraponer la dilucidación acerca del papel de la doctrina de las ideas de ideas de Bennett y de Curley. Aunque ambos concuerdan en que esta doctrina puede servir a una teoría de conocimiento y conciencia de sí en el sistema de Spinoza, sólo el primero hace una distinción entre conocimiento y conciencia obviando implicaciones epistémicas improbables tales como ser consciente de todo lo que acontece en nuestro cuerpo. Si bien Curley acepta que en los términos en los que habla de conciencia no intenta defender que en Spinoza se sepa todo aquello que pasa en nuestro cuerpo, no hace la distinción entre conciencia y conocimiento. Dicha distinción pudo haber sido crucial para evitar ambigüedades epistémicas en sus objetivos. Así, Bennett, más que criticar negativamente la postura de Curley (en el supuesto de que en la obra de Bennett se confrontara directamente a Curley), proporciona consideraciones que, acatadas por él, pueden reforzar su dilucidación.

Pese a esta distinción conceptual entre Bennett y Curley cabe recordar que a ambos los identifica una interpretación de la doctrina del paralelismo correspondiente a que las modificaciones de los atributos divinos expresan cosas singulares. Si la doctrina de las ideas de ideas sirve a manera de conocimiento (o conciencia en el caso de Curley) de lo que nos compone, presuponemos que la mente humana, al estar constituida por una idea del cuerpo, expresa primero a cada componente de nuestro cuerpo y luego a nuestro cuerpo. Como afirmamos que aquello que expresa la idea que constituye a la mente humana es un cuerpo, nos movemos en una interpretación del paralelismo en la que las modificaciones de los atributos expresan a una cosa singular. Si hubiéramos interpretado que aquello que expresa tal o cual idea constituyente de la mente humana es su relación con Dios (un modo, de un atributo de Dios), estaríamos en la visión del paralelismo en la que las modificaciones lo expresan en última instancia. Por lo que debemos resaltar que tanto Bennett y Curley, pese a sus diferencias argumentativas, tienden a una idea de paralelismo en la que una cosa, y no Dios en última instancia, se expresa de dos maneras distintas (pensamiento y extensión). 


\section{Wilson: La 'sobrelectura' de Curley}

Margaret Dauler Wilson, de manera contraria a Bennett, critica a Curley de manera directa. Las consideraciones de Wilson se reducen a decir que ciertas interpretaciones clave de extractos de la obra de Spinoza que Curley utiliza para sustentar su postura en relación a la distinción entre mentes conscientes y no conscientes, son inadecuadas.

La primera crítica hacia Curley por parte de Wilson se centra en a la carta 58 dirigida a G.H. Schuller, donde aborda explícitamente el polémico tema de la libertad. Curley extrae de esta carta lo siguiente para mostrar que Spinoza intenta distinguir entre mentes conscientes y no conscientes: «Spinoza implica claramente que tales cosas como rocas no poseen conciencia (ver Ep. 58, IV:266)» (1969; 126). La referencia que marca Curley concuerda con un ejemplo al que acude Spinoza para distinguir entre libertad necesaria y constreñida y la libertad imaginaria humana.

En esa carta, Spinoza trata de explicar a Schuller el sentido en que habla de libertad. «Yo llamo libre a la cosa que existe y obra por la sola necesidad de su naturaleza; constreñida, por el contrario, a la que está determinada por otra a existir y obrar de cierta y determinada manera» (Ep. 58). Para ejemplificar lo anterior Spinoza recurre al ejemplo del movimiento de una roca. El movimiento de cierta roca depende de determinada causa externa y no de la decisión de la roca para moverse.

[...] suponga ahora, si le place, que la piedra, mientras continúa moviéndose, piensa y sabe que se esfuerza en todo lo posible en continuar moviéndose. Por cierto, ésta piedra, dado que sólo tiene conciencia de su esfuerzo y no es indiferente, creerá que es completamente libre y que persevera en el movimiento por ninguna otra causa, sino porque quiere. Y ésta es esa famosa libertad humana, que todos se jactan de tener y que solo consiste en esto: que los hombres tienen conciencia de sus deseos, pero ignoran las causas que lo determinan (Ep.58).

Como la roca actúa gracias a una limitación externa, no es libre. Si ésta fuera consciente, creería que es completamente libre (en el sen- 
tido en que se mueve porque ella lo decide y no porque otro la obliga). De esta manera, la afirmación de Curley respecto a que la carta en cuestión 'implica claramente' que cosas como rocas no son conscientes, es, como menciona Wilson, una 'sobrelectura' (overreading) del texto ya que la intención de Spinoza en tal carta no era distinguir entre mentes conscientes y no conscientes, sino ejemplificarle a Schuller su noción de libertad. «Curley evidentemente interpreta esto [la carta 58 de Spinoza] como una suposición contrafactual intencionada - la cual es razonable pero no creo que estrictamente necesaria para el texto» (Wilson 1999; 134).

La segunda crítica a Curley, elaborada por Wilson, concuerda con la consideración de Bennett que analizamos en el apartado anterior, esto es, una falta de precisión y distinción entre conocimiento y conciencia. Curley, al referirse a la proposición XIX de la segunda parte de la Ethica, interpreta que tener una idea de una idea acerca de nuestro cuerpo es estar consciente de él (ver 1969; 128). La proposición postula lo siguiente: «La mente humana no conoce [cognoscit] al cuerpo mismo, ni sabe que exista, sino por las ideas de las afecciones por las que es afectado el cuerpo» (E IIP19). Resaltemos que Spinoza no usa la palabra conciencia, sino que usa conocer. Así, parece que Curley no hace distinción entre un término y el otro. «No hay contraste implícito, tan lejos como veo, entre tener una idea de una afección y ser consciente de esa afección» (Wilson 1999; 134). ¿Cuáles son las consecuencias de la falta de distinción entre conocimiento y conciencia en Curley? Básicamente una serie de confusiones epistémicas basadas en precisiones de términos que no pertenecían a la época en la que se desenvuelve Spinoza, por lo que algunos críticos (Jon Miller, Bennett y Wilson) consideran que el hablar de conciencia o adjudicarle el tema de la conciencia a Spinoza es un anacronismo. ${ }^{5}$

La tercera crítica a Curley es suscitada por una particular interpretación de la proposición $\mathrm{XX}$ de la segunda parte de la Ethica de donde Curley extrae que las ideas de ideas son exclusivas para el hombre. Para Curley la «existencia de ideas de ideas se demuestra

\footnotetext{
${ }^{5}$ Jon Miller hace una recapitulación histórica referente al uso de conciencia en la modernidad temprana con el objetivo de mostrar esto (ver Miller 2007).
} 
sólo para las mentes humanas (E IIP20)» (1969; 128). Si bien el criterio para identificar seres conscientes de seres no conscientes es que unos tienen ideas de ideas según Curley, entonces las mentes humanas son las únicas conscientes. Curley, al considerar que «aunque Spinoza está dispuesto a hacer valer que todo está animado (en un sentido poco común del término), no está preparado para decir que todo excepto un ser humano es consciente» $(1969 ; 128)$ reafirma una exclusividad de la conciencia para las mentes humanas.

Miller, al inclinarse a las críticas por parte de Wilson a Curley, afirma que esta exclusividad es cuestionable: «no es del todo cierto que Spinoza 'dice' que sólo los humanos son conscientes. Esas son palabras de Curley, puestas en la boca de Spinoza como una interpolación de ciertos textos» (2007; 214). Margaret D. Wilson explica que la exclusividad de la conciencia para humanos según Curley puede ser puesta en duda desde la justificación de su afirmación. Cuando Curley afirma que las ideas de ideas sólo se demuestran para la mente humana hace referencia a la proposición $X X$ de la segunda parte de la Ethica. Tal proposición dice: «De la mente humana se da también en Dios la idea, o sea, el conocimiento [cognitio], que se sigue en Dios de la misma manera y dice relación a Dios de la misma manera que la idea o conocimiento del cuerpo humano» (E IIP20). Es posible pensar que la exclusividad de ideas de ideas para mentes humanas interpretada por Curley se extrae en el sentido en que dicha proposición establece que la mente humana tiene una idea o conocimiento del cuerpo humano, por lo que la mente humana tiene una idea de una idea, o si se prefiere, bajo la luz de la sustitución posible entre Idea y proposición que establece Curley, tiene una proposición de una proposición. Pese a que en la proposición en cuestión sugiere que la mente humana tiene ideas de ideas, Curley obvia el papel de Dios. Así, la exclusividad de la conciencia para el hombre se nubla.

La demostración de tal proposición explica que el pensamiento es un atributo de Dios que sufre ciertas afecciones o modificaciones. La mente humana es una de esas modificaciones del atributo del pensamiento. Si toda modificación de tal o cual atributo está en Dios por la proposición XV de la primera parte de la Ethica -que establece que todo cuanto es, es en Dios, debido a que Dios es la única 
substancia y no hay nada fuera de él-, entonces diremos que la mente humana está en Dios. Si Dios tiene una idea de la mente humana que a su vez tiene una idea del cuerpo humano, se dirá que Dios cumple con la condición para calificarlo como consciente. Si esto es válido, la exclusividad que Curley afirma de la mente humana como consciente es inadecuada. Aparte del hombre, Dios es consciente pues también tiene ideas de ideas. Así, la doctrina de las ideas de ideas, para Wilson, no cumple satisfactoriamente la distinción entre mentes no conscientes y conscientes, debido a que tal distinción en Curley es exclusiva para el hombre y su entorno con la omisión de Dios (ver 1999; 135).

Pese a estas críticas correspondientes a la interpretación particular de Curley a 1) la carta 58 de Spinoza a Schuller, 2) a la proposición XIX de la segunda parte de la Ethica y la falta de distinción entre los términos conocimiento y conciencia, y 3) a la proposición XX de la segunda parte de la misma donde se muestra que la conciencia o las ideas de ideas no son exclusivas de la mente humana, Wilson no desacredita que en la Ethica se hable de conciencia. Aunque en efecto se habla de ella, no se hace en los mismo términos que Curley plantea.

Para explicar esto Wilson acude al escolio de la proposición XIII de la segunda parte de la Ethica donde Spinoza dice:

diría [desde un punto de vista general] que cuanto más apto es un cuerpo, respecto de los demás, para actuar sobre y padecer varias cosas a la vez, tanto más apta es su mente, respecto de las demás, para percibir varias cosas a la vez; y cuanto más dependen las acciones de un cuerpo de éste solo, y cuanto menos lo acompañan otros cuerpos en la acción, tanto más apta es su mente para entender distintamente. Y por eso podemos conocer la excelencia de una mente sobre las otras (E IIP13s).

Según Wilson el anterior pasaje muestra que Spinoza reconoce que hay grados de excelencia o distintos entendimientos de distintas mentes (ver 1999; 136). Unas pueden percibir más cosas que otras así como pueden percibir menos en comparación. De esta manera si existe un individuo con, digamos, un sistema nervioso más complejo que otro, se dirá que es más excelente que el otro y que, por lo 
tanto, su mente tiene más entendimiento que la del segundo. Así, podríamos hablar de conciencia, o de conocimiento (al aceptar una distinción entre conceptos) en un sentido distinto al de Curley. El problema se ubicaría en el campo del conocimiento (como Bennett señala) y no se basaría meramente en la doctrina de las ideas de ideas sino que también en una teoría de grados de excelencia. Wilson, por su parte, no ahonda en la doctrina de los grados de excelencia aunque la reconoce. Sólo se limita a establecer que una explotación de tal tendencia es plausible, mas implicaría una búsqueda y una interpretación forzada del sistema de Spinoza, ya que parece que Spinoza no intentó de manera alguna tratar el problema de la distinción entre mentes conscientes y no conscientes.

Bien podríamos decir que las consideraciones sobre Curley por parte de Wilson y Bennett, más que solucionar un problema, abren posibilidades de estudios. Tal es el caso del naturalismo incremental y de una posible teoría de la representación en Spinoza. Aunque Wilson apueste por una 'sobrelectura' en los textos de Spinoza con respecto a la distinción entre mentes conscientes y no conscientes, una diversidad de estudiosos, entre los que está Don Garrett, intentan dar razón a tal problemática de manera alternativa a los antecedentes de la misma (Curley).

Como hemos visto, el problema de la distinción entre mentes conscientes y no conscientes ha sido tratado bajo una visión de paralelismo según la cual aquello que se expresa es cierta cosa de dos modos distintos y no a Dios mismo. Lo que resta analizar es si a las alternativas suscitadas como respuesta al problema que manifiesta Curley les subyace tal interpretación del paralelismo, o bien, si bajo otra interpretación del paralelismo el problema de la distinción entre mentes conscientes y no conscientes surge como tal.

En el caso de las consideraciones hechas por Margaret Wilson a Curley encontramos provocaciones dirigidas hacia una interpretación de paralelismo que no sólo se refiere a la relación a manera de identidad entre un objeto extenso (modo del atributo de la extensión) y una idea (modo del atributo del pensamiento), sino a una relación con Dios. La prueba de esto resalta cuando Wilson se refiere a las mentes simplemente como ideas de Dios (ver 1999; 130). Cuando consideramos a las mentes sólo como una idea de una idea de un objeto 
extenso omitimos su relación con Dios. Pero cuando aceptamos que las mentes son ideas de Dios subrayamos esta relación. Así, lo que es una mente para tal o cual individuo, es sólo una idea para Dios. En el segundo caso en el que consideramos la relación, diremos que se está dentro de una interpretación de la doctrina del paralelismo en la cual las ideas (o cualquier modo de cualquier atributo) expresan (explican, envuelven) a Dios. En el primer caso, en el que atendemos exclusivamente a la expresión de una idea de tal idea de determinado objeto extenso, mas omitimos la relación con Dios, nos movemos en una interpretación de la doctrina del paralelismo en la que aquello que expresa un modo de un atributo es sólo una cosa singular (una roca, un reloj, la idea de tal roca, etc.) por lo que, al omitir a Dios, ésta es inadecuada para el sistema de Spinoza. Tanto Bennett como Curley hablan en estos últimos términos sobre el paralelismo. Wilson invita a pensar en los primeros términos. Así, nos queda ver si a esas propuestas alternativas al problema de la distinción entre mentes conscientes y no conscientes subyace la interpretación del paralelismo que no omite la relación de los modos con Dios y si, en efecto, le da una respuesta satisfactoria al problema señalado.

\section{Garrett: Naturalismo incremental e inherencia}

Don Garrett publica en 2008 su artículo Representation and Consciousness in Spinoza's Naturalistic Theory of the Imagination, en el que plantea lo que denomina naturalismo incremental (incremental naturalism). Su intención es, con lo planteado, clarificar ciertos enigmas (puzzles) que suscita la filosofía de Spinoza. Entre los cuatro principales que maneja se encuentra el de la conciencia. ${ }^{6}$ Para esta clarificación resulta importante considerar el planteamiento del problema de la imaginación que, según Garrett, presenta un fuerte vínculo con el de la conciencia.

Spinoza define a la imaginación (imaginatio), de acuerdo a Garrett señalando: «las afecciones del cuerpo humano, cuyas ideas

\footnotetext{
${ }^{6}$ Los restantes son: imaginación, representación y expresión del comportamiento (ver Garrett 2008).
} 
representan cuerpos externos como si estuvieran presentes ante nosotros, imágenes de las cosas, aun cuando no digan relación a las figuras de las cosas. Y cuando la mente considere de esta manera los cuerpos, diremos que imagina» ( $E$ IIP17s).

Garrett contrapone lo anterior a la proposición XII de la segunda parte de la Ethica: «Cuanto acontece en el objeto de la idea constituyente de la mente humana, debe ser percibido por la mente humana, o sea, de tal cosa se dará en la mente necesariamente la idea; esto es, si el objeto de la idea que constituye la mente humana, es un cuerpo, nada podrá pasar en este cuerpo que no perciba la mente» (E IIP12).

Garrett interpreta que aquella percepción de cualquier cosa que pase en el cuerpo que constituye la mente, será a través de la imaginación. Esto debido a que cuando se imagina, se crea una imagen de las afecciones del cuerpo humano cuyas ideas representan un cuerpo externo como presente. Así, "parece que, para Spinoza, la mente de un ser humano percibe por medio de la imaginación todo lo que pasa en su cuerpo» $(2008 ; 6)$. Pero a Garrett no le satisface esta consideración sobre la imaginación y acude al siguiente escolio para conseguir algo de sumo interés:

todo lo que hemos mostrado aquí es absolutamente común y pertenece por igual a los hombres y a los restantes individuos, todos los cuales son seres animados, aunque en grados diversos. Pues en cualquier cosa se da en Dios necesariamente una idea, de la cual el propio Dios es la causa, como lo es de la idea del cuerpo humano: y así cuanto hemos dicho de la idea del cuerpo humano ha de decirse necesariamente de la idea de cualquier cosa ( $E$ IIP13s).

Así, Garrett postula que cada 'individuo' o 'cosa singular' (res singularis) (incluso las no humanas) tiene una idea que está relacionada con tal individuo de la misma manera que la mente humana está relacionada con el cuerpo humano (por lo que las cosas no humanas también tienen 'mente' como Curley señala (1969; 126)). Si seguimos esto, entonces cada 'individuo' (sea un ser humano o no lo sea) percibe por imaginación lo que pasa en su cuerpo $(2008 ; 6)$. Esto corresponde precisamente al enigma de la imaginación, ya que ¿cómo 
es posible que un individuo no humano imagine todo lo que pasa en su cuerpo?

Este enigma se vincula con el de la conciencia cuando consideramos que la sorprendente amplitud de la imaginación se puede matizar con imaginaciones conscientes y no conscientes, o por lo menos, imaginaciones menos o más conscientes. ${ }^{7}$ Cuando Curley apuesta a una distinción entre mentes conscientes y mentes no conscientes, se deja llevar por ciertos pasajes de la Ethica en los que parece que se restringe la conciencia a los seres humanos. ${ }^{8}$ Pero, si la argumentación de Wilson es correcta, esta restricción es imposible a la luz de la proposición XX de la segunda parte de la Ethica donde Dios también cumple con la condición de la conciencia que implica tener ideas de ideas. Garrett, con respecto a la argumentación de Wilson, dice que si bien la condición para hablar de individuos conscientes es que tengan una idea de, entonces, no sólo Dios y el hombre son conscientes, sino que todo individuo lo es. Si atendemos al escolio de la proposición XIII anteriormente citado tendremos que si el hombre tiene ideas de, entonces esta característica es «absolutamente común y pertenece por igual a los hombres y a los restantes individuos». El hecho de que todo individuo tenga conciencia, es lo que caracteriza lo enigmático del tema de la conciencia en Spinoza.

Garrett nota que, en lo que concierne al enigma de la conciencia, no puede haber solución satisfactoria al distinguir lo consciente de lo no consciente. Desde la parte quinta de la Ethica Garrett encuen-

\footnotetext{
${ }^{7}$ Curley procedió de manera similar. Al ver que todo individuo tenía mente, trató de ver si era posible distinguir mentes conscientes de no conscientes. Su respuesta se redujo a que algunos tenían ideas de ideas y otros no. Garrett responderá de manera distinta considerando una respuesta en grados. Esto es, imaginaciones menos conscientes que otras, no imaginaciones conscientes e imaginaciones no conscientes.

${ }^{8}$ Garrett muestra cuatro casos en particular para ejemplificar lo anterior: 1) «los hombres creen que son libres por la sola causa de que son conscientes [consii] de sus acciones e ignorantes de las causas que los determinan» (E IIIP2s); 2$)$ «La mente [...] se esfuerza por preservar en su ser por una duración indefinida, y es consciente [conscia] de este esfuerzo suyo» ( $E$ IIIP9);3) «entre apetito y deseo no hay diferencia alguna, sino que el deseo se relaciona generalmente con los hombres, en cuanto son conscientes [conscii] de su apetito [por lo que] deseo es el apetito con conciencia [conscientia] de sí mismo» (E IIIP9s); 4) «como el hombre es consciente [conscius]de sí merced a las afecciones que lo determinan a actuar, quien hace algo que se imagina que afecta de alegría a los demás, será afectado de alegría con la conciencia [conscientia] de sí mismo como causa» (E IIIP30D) $(2008 ; 8)$.
} 
tra que el tema de la conciencia se toma a manera de grados mayores o menores. Específicamente Garrett nota que 1) «cuanto más aventaja cada cual en este género [tercero] de conocimiento, tanto más consciente [conscius] es de sí mismo y de Dios, esto es, tanto más perfecto y feliz es» (E VP31s); y 2)

[...] quien, como niño infante, posee un cuerpo apto para poquísimas cosas y dependiente en grado extremo de las causas externas, tiene una mente que, considerada por sí sola, casi no es consciente de sí misma, ni de Dios, ni de las cosas; y, por el contrario, quien posee el cuerpo apto para muchas cosas, también posee una mente que, considerada por sí sola, es sobremanera consciente de sí misma, de Dios y de las $\operatorname{cosas}(E$ VP39s).

Las anteriores citas claramente sugieren una visión de conciencia a manera de grados y de conocimiento tanto de Dios, como de uno mismo. Esto sugiere que el problema de la conciencia no se soluciona con la posesión o la falta de ideas de, sino de grados. La postura de Garrett respecto a los grados, bien puede ser considerada otro enigma ya que ¿cómo Spinoza puede sostener que hay individuos menos o más conscientes que otros?

Garrett trata estos enigmas bajo la clarificación de ciertas doctrinas encontradas en el propio sistema de Spinoza, en las que intenta encontrar una solución apegada a sus textos sin recurrir a elementos externos; lo que a fin de cuentas mostraría que 1) en Spinoza se puede abordar el tema de la conciencia dentro de ciertos parámetros distintos a los discutidos por Curley; y 2) que al explicar los enigmas propiciados con las obras de Spinoza con lenguaje anacrónico (como en el caso de Curley), los enigmas no se disuelven, sino que se exacerban (prueba de ello es la discusión que entablan tanto Bennett, como Wilson y Curley). A las doctrinas mencionadas por Garrett les subyace una doctrina que bien cabe mencionar: la de la inherencia.

La inherencia básicamente es aquella tendencia a afirmar que la substancia Dios es inherente a todo, ya que todo está en ella y no es sino por ella. Esta doctrina, podríamos decir, es la que resguarda el carácter metafísico del sistema de Spinoza (ver Garrett 2008; 10). 
En la primera parte de la Ethica, al mencionar que todo está en Dios vemos que a todas las cosas singulares les es inherente Dios. Nuevamente, no entendamos cosas singulares (res singulares) como modo perteneciente y exclusivo a la extensión, sino a cualquier atributo. Las cosas singulares son modificaciones de los atributos de Dios. Éstas están en él. Supongamos cierta modificación de la extensión. A esta modificación le será inmediatamente inherente un atributo. A este atributo le será inmediatamente inherente la substancia. Por lo que a esta modificación le será inherente Dios en última instancia.

A esta doctrina le sigue la correspondiente a la individualidad. Esta doctrina se refiere al sentido en que se trata a los individuos en la Ethica. Spinoza dice:

Cuando algunos cuerpos de la misma o diversa magnitud son compelidos por los demás de tal manera que se articulen entre sí, o, si se mueven con el mismo o diversos grados de velocidad, que se comuniquen sus movimientos entre sí según una cierta razón, diremos que esos cuerpos están unidos entre sí y que todos componen a la vez un mismo cuerpo o individuo, que se distingue de los demás por esta unión de cuerpos (E IIP13DEF ).

Garrett aclara que la noción de individuo, en la Ethica, no debe tomarse como solamente una unión de cuerpos extensos. La noción de individuo debe ser relacionada con la noción de cosa singular (res singularis) en el sentido en que el individuo es finito así como una cosa singular (E IIDEF7). Estos individuos o cosas singulares finitas guardan una característica que Garrett señala oportunamente. Cada individuo o cosa singular, en cuanto es un cuerpo complejo, persiste en su naturaleza al mantener el orden de comunicación y movimiento entre sus partes (ver 2008; 11). Esto lo explica Spinoza a razón de retención (retinabit) de la naturaleza del individuo en el siguiente lema: «Si de un cuerpo o un individuo que se compone de varios cuerpos se segregan algunos cuerpos y al mismo tiempo ocupan su lugar oros tantos de la misma naturaleza, tal individuo retendrá su naturaleza como antes, sin mutación alguna de forma» (E IIP13L4). Así, respectiva comunicación y movimiento entre las partes de un cuerpo extenso será la forma o bien la naturaleza de cierto individuo. 
El individuo persistirá o retendrá esa comunicación entre partes. A esto, Garrett lo denomina la doctrina de la preservación de la forma (pattern) extensa y básicamente dice que consiste en la persistencia de un individuo para mantener la forma de comunicación entre sus partes (ver 2008; 12).

Ahora bien, si recurrimos al paralelismo característico de Spinoza que está manifestado en la proposición VII de la segunda parte de la Ethica, veremos que la doctrina de la preservación de la forma no es sólo para cosas extensas sino también para modificaciones del pensamiento. Si el «orden y conexión de las ideas es el mismo que el orden y conexión de las cosas [rerum]» (E IIP7), entonces un individuo que esté conformado por cuerpos extensos persistirá en mantener la comunicación y el movimiento entre sus partes, al igual que las ideas de esos cuerpos. A esto Garrett lo denomina la doctrina de la preservación de la forma del pensamiento y la define como la «persistencia de un individuo a través del tiempo [que] consiste no en la igualdad [sameness] de la substancia subyacente [Dios] sino, en la medida en que esté expresado y concebido a través del pensamiento, en la persistencia de una idea de una forma distintiva de comunicación de movimiento entre partes» $(2008 ; 12)$.

Esta noción de persistencia y retención de la comunicación entre partes de un individuo extenso o de pensamiento, Garrett la vincula fuertemente con la doctrina característica de Spinoza referente al conatus. Tal doctrina se encuentra postulada en la proposición VI de la tercera parte de la Ethica que dice: «Cada cosa [res], en cuanto está en ella, se esfuerza por perseverar en su ser» (E IIIP6). La palabra conatus indica, según Garrett, este esfuerzo por perseverar en la esencia actual de determinada cosa. El esfuerzo es identificado por Spinoza como una potencia [potentia] de una cosa cualquiera ( $E$ IIIP7D). Garrett por ello postula a la doctrina del conatus como una doctrina de potencia (power). Así, la doctrina del conatus como potencia, para Garrett, se refiere a que la "potencia [power] de cada cosa singular es su conatus, que es su esfuerzo para perseverar en su ser» $(2008 ; 12)$. Así, la persistencia o esfuerzo de un individuo (sea extenso o de pensamiento) por mantener la forma de comunicación entre sus partes es su conatus o su potencia.

Este conatus o potencia no está restringido a ciertos individuos. 
Tanto individuos superiores a los hombres como inferiores en una escala gradual tienen este conatus. La diferencia entre ellos es precisamente el grado de complejidad de los cuerpos que los conforman así como el esfuerzo o persistencia por mantener determinada comunicación de movimiento entre partes. Es por esta distinción gradual que algunos «cuerpos individuales, sin embargo, tienen muchos más recursos que una roca o una tostadora para mantener sus distintivas formas de comunicación de movimiento que constituye su existencia continua» (Garrett 2008; 13). Cuando la potencia o el esfuerzo de determinado individuo es sobrepasado por algún otro individuo que lo afecta y que goza de un esfuerzo mayor para conservar sus partes, el individuo primero cambia sus partes y pierde su existencia. Supongamos que una bala disparada afecta a un vaso de cristal de tal manera que el vaso de cristal se rompe. Lo que pasó ahí es que el individuo de cristal tenía un grado menor de conatus y no pudo mantener sus partes comunicadas. La bala, está en un grado mayor de conatus a comparación del vaso de cristal. Pero estará en un grado menor de conatus al compararse con otro individuo, digamos, una fundidora. Lo anterior sugiere que hay grados de conatus o de perseverancia por mantener las partes componentes de tal o cual individuo comunicadas.

El grado de esfuerzo, persistencia o, como Garrett lo llama, potencia (power) de cada individuo para mantener sus partes comunicadas, está relacionado con el grado de perfección. Cuando Spinoza define tristeza dice que es «el paso del hombre de una perfección mayor a una menor» (E IIIDEFA3). Este paso a una perfección menor es el «acto por el que se disminuye o limita la potencia de actuar» $(E$ IIIDEFA3e). Lo anterior le parece suficiente a Garrett para postular que los grados de perfección se vinculan con los grados de potencia o esfuerzo (conatus) y a su vez, con los grados de realidad ya que Spinoza por «realidad y perfección entiend[e] lo mismo» ( $E$ IIDEF6). Al seguir a Garrett, podemos ver en Spinoza que la distinción entre individuos se da a través de la graduación de realidad, perfección y conatus.

[...] tampoco podemos negar que las ideas difieren entre sí como los objetos mismos y que la una es más excelente que la otra y contiene más de realidad, en la misma medida en que el objeto de la una es más excelente que el de la otra y contiene más de realidad; por esta razón, 
para determinar en qué difiere la mente humana respecto de las demás y en qué las aventaja, nos es necesario, según lo manifestamos, conocer la naturaleza de su objeto, es decir, del cuerpo humano [...] desde un punto de vista general, diría que cuanto más apto es un cuerpo, respecto de los demás, para actuar sobre y padecer varias cosas a la vez, tanto más apta es su mente, respecto de las demás, para percibir varias cosas a la vez; y cuanto más dependen las acciones de un cuerpo de éste solo, y cuanto menos lo acompañan otros cuerpos en la acción, tanto más apta es su mente para entender distintamente. Y por esto podemos conocer la excelencia de una mente sobre las otras (E IIP13s).

Estas distinciones en orden de perfección y existencia no son entre las mentes de los hombres solamente, sino de todos los individuos. Cada individuo o cosa singular, describe Garrett, goza de cierto grado de perfección, realidad y conatus con respecto a otras cosas singulares, entre ellas, los hombres, animales, objetos de cocina, etc. A la consideración de que cada cosa singular tiene cierto grado de potencialidad (o conatus), perfección o realidad, Garrett la denomina la doctrina de la variabilidad de potencia (power).

Esta potencialidad o esfuerzo no sólo compete a la extensión. Si bien las cosas (res), incluyendo extensas, guardan un mismo orden y conexión con las ideas, también las ideas guardarán cierta potencialidad. La potencialidad del pensamiento (cogitandi potentia) se explica desde que «toda la potencia [power] es la potencia de Dios, el poder de una cosa singular es una expresión o parte de la potencia de Dios. Spinoza llama a la potencia de Dios como expresada y concebida bajo el atributo del pensamiento 'potencia de pensar'» $(2008 ; 15) .{ }^{9}$ Cada individuo o cosa singular tiene cierta potencia de pensar, pero en grados diversos. La tostadora, el reloj, el perro, el simio, y el hombre tienen esa potencia de pensar pero no en el mismo grado. "Así, algunas de las ideas de Dios tienen más potencia de pensar que otras, y éstas pueden aumentar o disminuir en su potencia de pensar. Lo mismo es verdad para ideas

\footnotetext{
${ }^{9}$ Nótese que Garrett, al marcar la potencia de Dios, usa el término expresión en un sentido en el que podríamos afirmar sin duda alguna que las modificaciones de los atributos expresan a Dios y no a las cosas singulares.
} 
particulares en la mente humana y para otras mentes finitas» (2008; 15). Según el grado de conatus que tenga tal o cual individuo, argumenta Garrett, se tendrá cierto grado de potencia de pensar. A esto Garrett lo denomina la doctrina diferencial de la potencia de pensar. La diferencia entre individuos o cosas singulares surge según el grado de potencia de pensar en relación a un determinado nivel de conatus.

Con la anterior argumentación, Garrett nota que en Spinoza las distinciones entre individuos no serán por falta o posesión de alguna característica en particular, sino que radicará en una distinción por grados. Garrett posibilita ver esta distinción gradual al tener en cuenta las doctrinas que anteriormente señalamos (inherencia, individualidad, conatus, potencialidad de extensión y pensamiento), y al apostar por lo que él llama naturalismo incremental.

Por 'naturalismo' me refiero al proyecto de integrar plenamente el estudio y entendimiento de los seres humanos, incluyendo la mente humana, en el estudio y entendimiento de la naturaleza, de modo que los seres humanos no sean contrastados con la naturaleza sino que en lugar de eso sean entendidos como entidades gobernadas en última instancia por los mismo principios que gobiernan a todas las otras cosas. Por 'incrementalismo' me refiero a la metodología para tratar importantes explicaciones de propiedades y relaciones no simplemente como presentes o ausentes sino como propiedades y relaciones que están generalmente presentes en grados mayores o menores $(2008 ; 18)$.

Atender al naturalismo incremental para la solución de los enigmas que anteriormente señalamos implicaría, entonces, no considerar a la humanidad como algo no natural, sino como una expresión de la naturaleza. Esto, podríamos pensar, encajaría con una visión de paralelismo según la cual las modificaciones de los atributos divinos están vinculados con Dios, expresándolo en última instancia. Pero antes de apresurar conclusiones, veamos cómo se resolverían los dos enigmas principales que anunciamos: el de la imaginación y el de la conciencia.

El enigma de la imaginación correspondía a que todo individuo (sea humano o no) percibe lo que pasa en su cuerpo. Garrett con- 
siderará que la percepción de cada individuo pertenecerá a cierto nivel de la potencia de pensar y, por lo tanto, de cierto nivel de conatus. Esto suscita que lo desconcertante del enigma (que individuos rudimentarios como rocas y tostadoras imaginen) sea reafirmado. En efecto, en lo que corresponde al sistema de Spinoza, todo individuo tiene potencial de pensar, pero como dice Garrett: «sería un error suponer que la doctrina [de la imaginación] es de algún modo una consecuencia indeseada o no intencionada para Spinoza, ya que constituye un elemento clave en su programa de naturalismo incremental» $(2008 ; 19)$.

El decir que todo individuo o cosa singular tiene la potencia de pensar, no quiere decir que todo individuo sea completamente igual al otro. Lo que distingue a este de aquel individuo en tanto que ambos tienen la potencia de pensar, es que no tienen el mismo grado de realidad, perfección y conatus. Individuos rudimentarios como rocas o tostadoras, tienen menos conatus que el hombre por ejemplo. La roca y la tostadora tienen la potencia de pensar, pero eso no implica que piensen de la misma manera en que un humano lo hace. Debido a que un hombre es más complejo y tiene más perfección, realidad, conatus y potencia de pensar que una roca, es capaz de muchas más cosas que la roca. Puede, por ejemplo, percibir muchas cosas a la vez, cosa que la roca no puede hacer. Así, aunque todo individuo tenga esta potencia de pensar, no quiere decir que todos ejerzan esa potencia de la misma manera, en el mismo grado, y con la misma perfección y realidad. De esta manera se explica el enigma de la imaginación que suscita el sistema de Spinoza.

En el caso de la conciencia, teníamos que el problema era comprender cómo unos individuos (no necesariamente hombres) eran conscientes pero en grados distintos. Garrett precisa que este problema se atiende sólo si consideramos que tener conciencia en Spinoza es equivalente a tener una idea de, por ejemplo, lo que pasa en nuestro cuerpo. De esta manera todos los individuos, al tener una idea de lo que pasa en sus respectivos cuerpos, son conscientes. ${ }^{10}$

\footnotetext{
${ }^{10}$ Garrett ejemplifica esto con dos proposiciones que tienen el mismo objetivo en el sistema de Spinoza. «M está consciente de $\mathrm{O}$ » $\mathrm{y}$ « $\mathrm{M}$ tiene una idea de $\mathrm{O}$ », donde $\mathrm{M}$ es una mente y $\mathrm{O}$ su objeto (ver 2008; 23).
} 
De acuerdo con Garrett, en Spinoza se puede hablar sin problema alguno de que todos los individuos son conscientes, pero en cierto grado. El grado de conciencia de cada individuo se vincula con el grado de su potencia de pensar así como con el grado de su conatus. Cuando un individuo es más capaz que otro al percibir más cosas que pasan en su cuerpo a comparación de un individuo inferior, se dirá que estos son distintos pero sólo porque uno tiene un grado mayor o menor de conciencia (de perfección, realidad y conatus) y no porque uno tiene conciencia y el otro no. Es decir, «cuanto más aventaja cada cual en este género [tercero] de conocimiento, tanto más consciente [conscius] es de sí mismo y de Dios, esto es, tanto más perfecto y feliz es» ( $E$ V P31s). Así, el enigma de la conciencia, en el sistema de Spinoza, se clarifica al aludir a la noción de grados de perfección, potencia de pensar y conatus.

Ahora bien, ¿el que la mente de tal o cual individuo tenga «ideas de O», quiere decir que todo individuo tiene ideas de ideas? Si bien recordamos, Curley distinguía a la conciencia con la posesión de ideas de ideas, por su parte Garrett parece atender a la conciencia en sentido de ideas de $\mathrm{O}$ (no exclusivamente de ideas). Mientras para el primero sólo el hombre tenía conciencia, para el segundo todo individuo la tiene pero en grados distintos. Por lo que podemos afirmar que ni Curley ni Garrett hablan de conciencia en Spinoza en los mismos términos.

Si apostamos a la postura de Garrett, ¿diremos entonces que las ideas de ideas no son propias de los hombres, sino de cualquier individuo? No necesariamente. Garrett habla de conciencia en términos de «idea de O» y no de ideas de ideas. Un individuo con grado inferior puede tener, gracias a su potencia de pensar una idea de lo que acontece en su cuerpo. Pero ese acontecimiento puede no ser una idea, sino, al seguir las ejemplificaciones de Bennett que con anterioridad tratamos, puede sólo ser la idea de un objeto, esto es $\mathrm{I}(\mathrm{x})$.

Cuando un individuo de grado de perfección y potencia de pensar inferior al de un hombre tiene una idea de (x), es decir I(x), cumple con el criterio de conciencia del que habla Garrett. Tal individuo es consciente. Pero no necesariamente tiene una idea de una idea. El hombre, por ejemplo, al ser un individuo con un grado mayor de 
potencia de pensar y perfección, es capaz de abarcar más cosas a la vez. Él puede tener una idea de una idea $\mathrm{I}(\mathrm{I}(\mathrm{x}))$ pero eso no quiere decir que los individuos inferiores no sean conscientes. El que el hombre sea capaz de tener ideas de ideas sólo dice que el hombre pertenece a un grado mayor de perfección, conatus y potencia de pensar que ciertos individuos.

Así, aunque hablar de ideas de ideas no sea el criterio adecuado para hablar de seres conscientes y no conscientes, es una manera de mostrar un grado superior de determinado individuo a comparación con otro (esto bajo la luz del naturalismo incremental). Por lo que, aunque ideas de ideas no sea la manera idónea para hablar de conciencia en Spinoza, eso no implica que los hombres y otros individuos de grado superior no tengan ideas de ideas. Estos individuos de grado superior tan pronto como «sabe[n] algo, sabe[n], por eso mismo, que lo sabe[n] y, a la vez, sabe[n] que sabe[n] lo que sabe[n], y hasta el infinito» (E IIP21s). El hecho de que haya individuos con ideas de ideas lo único que dice es que hay individuos de grados superiores a otros (rocas, tostadoras, etc.) en tal medida que pueden conocer sus cuerpos en grados superiores.

Ya considerado esto, cabe hacer un señalamiento más que muestra la médula de la confusión de autores como Curley y Bennett. Bien sabemos que la doctrina del paralelismo radica principalmente en lo expuesto en la proposición VII de la segunda parte de la Ethica, que dice que el «orden y conexión de las ideas es el mismo que el orden y conexión de las cosas» (E IIP7). Garrett toma a la proposición anterior como la doctrina del paralelismo; sin embargo de la misma deriva una doctrina más: la doctrina de la identidad de modo (Mode Identity Doctrine (ver 2008; 12)). Garrett caracteriza esta última doctrina con el siguiente extracto: «un modo de la extensión y la idea de este modo, son una y la misma cosa, pero expresada de dos maneras» ( $E$ IIP7s).

La novedad correspondiente a la doctrina derivada del paralelismo no debe suscitar problemática alguna. En efecto, aunque Garrett postula que son dos doctrinas, no admite que no guarden relación entre sí. Así que aunque son dos doctrinas, la relación entre ellas no debe ser obviada. ¿De qué le sirve a Garrett hacer esta separación? Cuando hablábamos de la interpretación característica de Curley con respecto al paralelismo anunciábamos que él creía que consistía 
en la «noción de Spinoza de que el modo de la extensión y la idea de ese modo son una y la misma cosa, expresada de dos maneras diferentes» $(1969 ; 120)$. Como vemos, la noción del paralelismo de Curley no corresponde a la noción del paralelismo de Garrett, sino a la de identidad de modo. La noción del paralelismo de Garrett resalta el mismo orden y conexión de ideas con cosas.

La separación de Garrett entre doctrinas propicia una lectura distinta de las obras de Spinoza. El paralelismo ya no implica que a la identidad de tal o cual individuo le pertenece un atributo de la extensión y uno del pensamiento (como en Curley), sino que las ideas y las cosas siguen un mismo orden y conexión. Este orden y conexión se relaciona fuertemente con la doctrina de la inherencia. $\mathrm{Si}$ a toda modificación de cualquier atributo le es inherente Dios, entonces este orden y conexión no se dice a manera de identidad, sino a manera de seguir un solo orden ya que estas modificaciones se encuentran en una sola y única substancia.

Si separamos la doctrina del paralelismo de la doctrina de la identidad de modo es más simple dar razón a la interpretación del paralelismo en que aquello que expresan las modificaciones es la inherencia del atributo y de Dios en última instancia, que permite considerar a todos las modificaciones bajo un mismo orden y conexión. La interpretación del paralelismo donde las modificaciones expresan una cosa singular y no a Dios mismo atenderá solamente a la doctrina de identidad de modo. ¿Esto quiere decir que a la interpretación del paralelismo donde aquello expresado por las modificaciones es en última instancia Dios le es extraña la doctrina de la identidad de modo? No. La identidad entre un modo del atributo de la extensión con uno del pensamiento no le es contraria a la visión del paralelismo donde se expresa a Dios; sin embargo necesita ciertas consideraciones.

Cuando hablamos de la identidad de tal o cual individuo, no nos referimos a una identidad substancial, puesto que esa sólo le pertenece a Dios. Cuando nos referimos a la identidad del reloj, nos referimos a cierta concordancia (en orden y conexión) entre una modificación del atributo del pensamiento con una de la extensión y no a una identidad substancial que permita equiparar al reloj con Dios (en caso de que se hiciera esta equiparación, tendríamos que la substancia no es única y que habría por lo tanto dos sustancias, lo cual es imposi- 
ble debido a la definición misma de substancia); sin embargo, cada modificación que concordó para hacer la identidad no substancial del reloj, expresarán a Dios debido a la inherencia del mismo. Así, podemos hablar de una identidad en dos sentidos. Uno substancial y el otro no. Cada cosa individual se puede ver como algo (identidad), y a la vez como relacionada con Dios (identidad substancial e inherencia). Podemos decir hasta aquí que la separación de doctrinas de Garrett propicia la oportunidad de concebir las obras de Spinoza bajo una interpretación del paralelismo que no omite en un solo momento la particular relación con la substancia.

Prueba de lo anterior resulta la afirmación de Garrett con respecto a la doctrina del poder del pensamiento que consiste en, a través de la doctrina de la inherencia, concebir a cada modificación del atributo del pensamiento con cualidades compartidas a las de Dios: «Dado que todo el poder es el poder de Dios, el poder de una cosa singular es una expresión [expression] o una parte [a share] del poder de Dios» (Garrett 2008; 15). El anterior uso de expresión concuerda con la tendencia que afirma que las modificaciones de los atributos no expresan a la cosa singular, sino a Dios. Por lo que podríamos decir que la propuesta de Garrett se ubica dentro de una interpretación del paralelismo alterna a la que tanto Curley como Bennett defienden.

Lo anterior prueba que a las problemáticas tratadas en este trabajo relacionadas con la distinción entre mentes conscientes y no conscientes les subyace una muy particular interpretación del paralelismo en las obras de Spinoza. Interpretación, que como vemos, resulta problemática e inadecuada al omitir la relación directa de las modificaciones de los atributos divinos con Dios. En cambio, bajo la interpretación defendida por Garrett (en la que se hace una distinción entre la doctrina del paralelismo y la doctrina de identidad de modo), vemos que los enigmas relacionados con que todo tenga la potencia de pensar se disuelven, lo que nos habla de una lectura inapropiada de los textos de Spinoza por parte de Curley y Bennett principalmente. 


\section{BIBLIOGRAFÍA}

Bennett, J. (1980). A Study of Spinoza's Ethics. Indianapolis: Hackett. Curley, E. (1969). Spinoza's Metaphysics: An Essay in Interpretation. Cambridge: Harvard University Press.

Garrett, D. (2008). Representation and consciousness in Spinoza's naturalistic theory of the imagination. En C. Huenemann (ed.), Interpreting Spinoza: Critical Essays (pp. 4-25). New York: Cambridge University Press.

Martin, C. (2007). Consciousness in Spinoza's Philosophy of Mind. The Southern Journal of Philosophy 45, 269-87.

Miller, J. (2007). The status of consciousness in Spinoza's concept of mind. En S. Heinämaa, V. Lähteenmäki y P. Remes (eds). Consciousness. From perception to reflection in the history of philosophy (203-220). Dordrecht: Springer.

Spinoza, B. (1988). Epistolario, O. Cohan (trad). Buenos Aires.

Spinoza, B. (1977). Ética, J. Gaos (trad). México: UNAM.

Wilson, M. (1999). Objects, Ideas and 'Minds': Comments on

Spinoza's Theory of Mind. En Ideas and Mechanism: Essays on Early Modern Philosophy (pp. 126-40). Princeton: Princeton University Press. 


\section{RESUMEN}

El papel de la conciencia en Spinoza no radica en la distinción entre hombres y demás individuos como afirma Curley, sino en los grados de perfección entre ellos. Para esto, apelaremos al naturalismo incremental propuesto por Garrett y defenderemos que Bennett y Curley tienen una visión del paralelismo inadecuada dado que las modificaciones de los atributos expresan no a la substancia, sino a una cosa singular debido a una confusión entre la doctrina del paralelismo y la de identidad de modo en Spinoza.

Palabras clave: Ideas de ideas; conciencia; paralelismo; cosas singulares; identidad de modo; naturalismo incremental.

\section{ABSTRACT}

The status of consciousness in Spinoza is not the distintion between men and the rest of individuals as Curley affirms, but the perfection grades between them. For this, we'll appeal to Garrett's incremental naturalism and we'll defend that Bennett and Curley have a special and inadequate paralelism's view which says that modifications of God's atributes express not to the substance, but a singular thing due to a confusion between the paralelism doctrine and mode identity doctrine in Spinoza.

Key words: Ideas of ideas; consciousness; paralelism; sigular things; mode identity; incremental naturalism. 